\title{
Coronavirus-2019. Consideraciones Generales
}

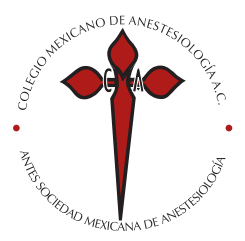

\section{Coronavirus-2019. General considerations}

\author{
Dr. Martín de Jesús Sánchez-Zúñiga,* Acad. Dr. Raúl Carrillo-Esper
}

\begin{abstract}
RESUMEN. De acuerdo a lo publicado por la OMS (Organización Mundial de la Salud) un primer caso de infección respiratoria aguda, de origen desconocido, apareció en la provincia de Hubei, China, en la ciudad de Wuhan (diciembre de 2019). Después de haberse descartado otros agentes etiológicos se logró el aislamiento de un nuevo coronavirus (07-01-2020), al que se denominó nuevo coronavirus (nCOV, COVID-19), en la actualidad nombrado como SARSCoV-2. Los coronavirus son patógenos importantes, pueden infectar el sistema respiratorio, gastrointestinal, hepático, nervioso, tanto de humanos como de aves, ganado, murciélagos, ratones y otros animales salvajes. Desde los brotes de SARS (síndrome agudo respiratorio severo) en 2002 y MERS (síndrome respiratorio de Medio Oriente) en 2012, se ha logrado demostrar la transmisión de estos virus entre humanos y animales.
\end{abstract}

ABSTRACT. According to what was published by the WHO (World Health Organization), a first case of acute respiratory infection, of unknown origin, appeared in the province of HUBEI, CHINA, in the city of WUHAN, (December 2019). After having ruled out other etiological agents, the isolation of a new coronavirus (7-01-2020) was achieved, which was called new coronavirus (nCOV, COVID-19), currently named SARS-CoV-2. Coronaviruses, being important pathogens, can infect the respiratory, gastrointestinal, hepatic, and nervous systems of humans and birds, livestock, bats, mice, and other wild animals. Since the outbreaks of SARS (Severe Acute Respiratory Syndrome) in 2002 and MERS (Middle East Respiratory Syndrome) in 2012, the transmission of these viruses between humans and animals has been demonstrated.
Palabras clave:

Coronavirus, COVID-19, SARS-CoV-2.

Keywords:

Coronavirus, COVID-19, SARSCoV-2.

\author{
* Unidad de Cuidados Intensivos. \\ Jefatura de Servicio. Instituto \\ Nacional de Rehabilitación «Luis \\ Guillermo Ibarra Ibarra». \\ ${ }^{\ddagger}$ Academia Nacional de Medicina. \\ División de Áreas Críticas del \\ Instituto Nacional de Rehabilitación \\ «Luis Guillermo Ibarra Ibarra». \\ Solicitud de sobretiros: \\ Dr. Martín de Jesús \\ Sánchez-Zúñiga \\ E-mail: mjsanchez@inr.gob.mx
}

Recibido para publicación: 08-04-2020

Aceptado para publicación: 16-04-2020

\section{INTRODUCCIÓN}

\section{Etiología y fisiopatología}

S ARS-CoV-2 es un virus ARN, de cadena positiva, monocatenaria, de forma esférica que en su superficie proyecta espículas proteicas, que en microscopía electrónica semejan a la corona solar. Taxonómicamente se clasifica como perteneciente a la orden Nidoviridae, familia Coronaviridae, subfamilia y grupo Orthocoronaviridae. Según el sero- y genotipo se identifican cuatro tipos: alfa, beta, gamma y delta (alphacoronavirus, betacoronavirus, gammacoronavirus y deltacoronavirus), siendo el nuevo coronavirus identificado como tipo beta; cabe señalar que este grupo es el de más alto riesgo, debido a su patogenicidad y ser causante de SARS y MERS (síndrome agudo respiratorio severo y síndrome respiratorio de Medio Oriente, respectivamente). Hasta el momento es incierto el hospedero de origen, se conoce que comparte material genético con el virus del SARS y del MERS en $60 \%$ y en $90 \%$ del coronavirus aislado en los murciélagos.
Existen cuatro proteínas estructurales que son esenciales para que el virus se replique, se ensamble e infecte al huésped: la proteína $\mathrm{S}$ (espiga) es la encargada de la unión a las células del huésped, este homotrímero tiene proyecciones extracelulares que le dan al virus la apariencia de una corona de picos. La proteína M (membrana) se conforma de tres dominios transmembrana que le dan la forma circular a la partícula viral y se une hacia el interior a la nucleocápside. La proteína $\mathrm{E}$ (envoltura) permite el ensamblaje y la liberación extracelular del virus. La proteína $\mathrm{N}$ (nucleocápside) está conformada por dos dominios que se une al ARN, se une a la proteína nsp3, para empaquetar el genoma del virus, además de ser antagonista del IFN (interferón) (Figura 1).

Casi dos terceras partes del ARN genómico del virus se utiliza como un molde o plantilla para la traducción directa de una poliproteína $1 \mathrm{a} / 1 \mathrm{ab}(\mathrm{pp} \mathrm{1a/1ab)} \mathrm{que} \mathrm{se} \mathrm{encarga} \mathrm{de} \mathrm{la}$ codificación de proteínas no estructurales (nsp, de las que se conocen 16, algunas con funciones aún no descritas) que son fundamentales para la formación del complejo de replicacióntranscripción del ARN del virión, la restante tercera parte, se utiliza para la codificación de proteínas estructurales, $\mathrm{S}, \mathrm{M}, \mathrm{N}$, 
E y otras proteínas que varían según el coronavirus, como la proteína $\mathrm{HE}$ (esterase de hemaglutinina), proteína $3 \mathrm{a} / \mathrm{b}, 4 \mathrm{a} / 4 \mathrm{~b}$.

El virus SARS-CoV-2 ingresa a la célula del huésped, a través de la adherencia de las proteínas $\mathrm{S}$ a los receptores celulares de ACE2, este receptor se expresa principalmente en células epiteliales del pulmón, intestino, riñón, corazón y vasos sanguíneos. La enzima convertidora de angiotensina 2 pertenece a la familia de ACE de dipeptidil carboxidipeptidasas, ACE1 y ACE2 tienen actividades tróficas diferentes. Existen dos formas de ACE2, una transmembrana y otra soluble, la primera de ellas es una proteína transmembrana con un dominio extracelular que sirve como receptor para la proteína S. Estudios en modelos murinos y humanos tratados con inhibidores de la enzima convertidora de angiotensina (iECAS) y ARA 2 (antagonistas de receptor de angiotensina 2) han demostrado la sobreexpresión de ACE2 transmembrana y soluble, que pueden hacerlos más susceptibles a la infección por coronavirus, esto debido a que la unión de SARSCoV-2 a la ACE2 atenúa la actividad residual (antiinflamatoria, vasodilatadora y antioxidante) y permite la sobreexpresión de ACE1 y angiotensina 2 con acciones finales sobre su receptor, principalmente proinflamatorias, vasoconstrictoras y oxidantes, mecanismos que explican parte de la lesión pulmonar observada en los individuos afectados (Figura 2).

El virus se transmite a través del contacto con gotas de una persona infectada (también se encuentra en la sangre, saliva, orina y las heces), aunque se han hecho observaciones de la posibilidad de transmisión por vía aérea, ésta no se ha confirmado, pero debe tenerse consideración especial cuando se generan aerosoles y la conjuntiva está expuesta, ya que el riesgo de transmisión es mayor.

Su período de incubación es de dos y hasta 11 días, en promedio de 6.4 días, de acuerdo a los reportes de diferentes países se recomienda considerar un período de incubación hasta de 15.5 días; la aparición de síntomas, en promedio, es después de cinco días, y de acuerdo con la Organización Mundial de la Salud hasta de 14 días después, de ahí que la recomendación de aislamiento o cuarentena abarque mínimo 14 días, algunos países han recomendado hasta 21 días de cuarentena con monitoreo de presencia del virus en pruebas serológicas.

\section{Diagnóstico}

El diagnóstico de SARS-CoV-2 debe hacerse de acuerdo a la evidencia de relación epidemiológica grupo A y síntomas grupo $\mathrm{B}$, y confirmarse con los estudios de reacción en cadena de polimerasa (RCP). Para fines prácticos deben considerarse factores de riesgo que aumentan la posibilidad de complicaciones graves, como neumonía de presentación atípica, síndrome de insuficiencia respiratoria aguda (SIRA), disfunción renal aguda, etcétera. La infección debe sospecharse si un factor de riesgo del grupo A está presente junto con dos síntomas del grupo B, o bien si tres síntomas del grupo B se encuentran presentes.

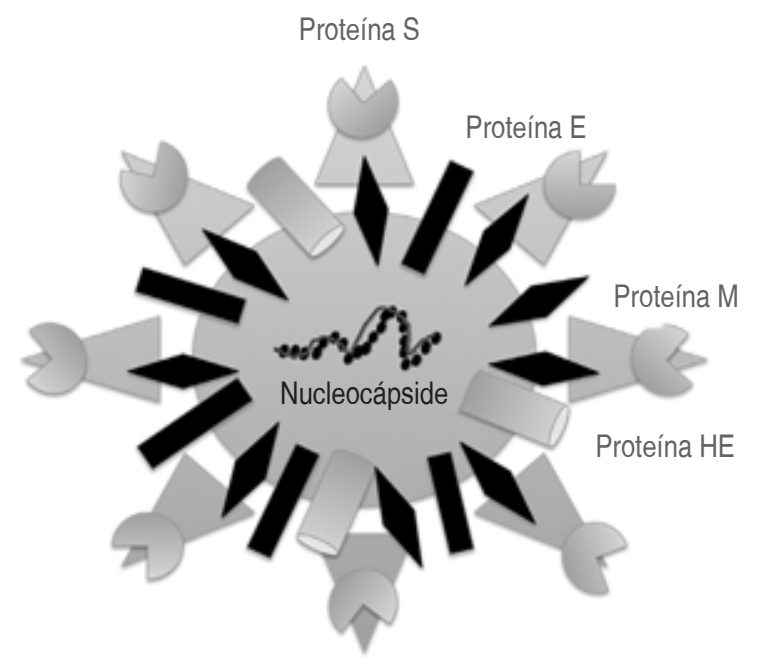

Proteína M: de membrana

Proteína E: de envoltura

Proteína S: de superficie, en pico o espiga

Proteína HE: de esterasa de hemaglutinina

Proteína N: de la nucleocápside

Genoma ARN

\begin{tabular}{|c|c|c|c|c|c|c|c|c|c|c|}
\hline $1 \mathrm{a}$ & & $S$ & $3 b$ & & $\mathrm{M}$ & & & & $\mathrm{N}$ & 10 \\
\hline & $1 b$ & & $3 a$ & $E$ & & \begin{tabular}{|l|l|}
6 & $7 a$ \\
\end{tabular} & $7 b$ & $9 a$ & $9 b$ & \\
\hline
\end{tabular}

Proteínas no estructurales (nsp)
Proteínas estructurales
Figura 1:

Características del virus SARS-CoV-2. 


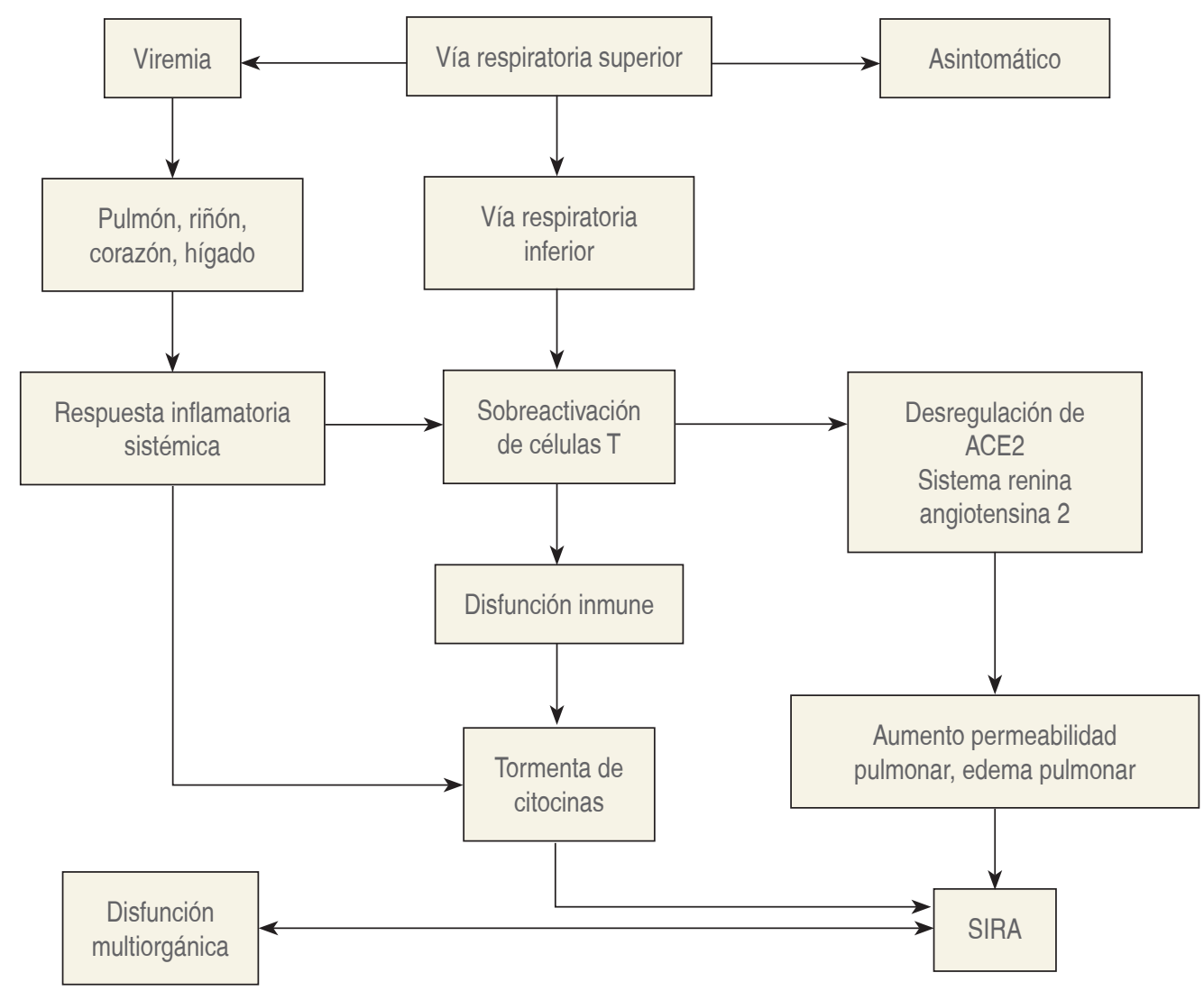

Figura 2:

Fisiopatología de la infección por COVID-19/SARS-CoV-2.
1. Factores epidemiológicos (grupo A): dos semanas antes del inicio de los síntomas:

a) Historial de viaje o residencia en una zona con casos confirmados de transmisión comunitaria.

b) Contacto con una persona confirmada con RPC (reacción de polimerasa).

c) Contacto con una persona sospechosa de infección en una zona de transmisión comunitaria.

2. Los síntomas, hallazgos de laboratorio y radiológicos (grupo B):

a) Fiebre, tos, disnea, estos tres síntomas son considerados los más frecuentes, pueden presentarse otros síntomas como diarrea (mayor actividad intestinal), cefalea, astenia, anosmia, etcétera. La disnea se considera síntoma de gravedad.

b) Los exámenes de laboratorio muestran, en etapas tempranas de la enfermedad, leucopenia y linfopenia hasta en $60 \%$ de los casos. Hasta $30 \%$ de los casos presentan leucocitosis, neutrofilia, transaminasemia, elevación de CPK (creatininfosfoquinasa), DHL (deshidrogenasa láctica) y mioglobina. La PCR (proteína C reactiva) está elevada, mientras que la procalcitonina se encuentra en rangos normales. Una característica significativa es que los individuos que desarrollan el síndrome o la tormenta de citosinas suelen presentar una reacción inflamatoria más agresiva con disfunción orgánica temprana (IL-2, IL-6, IL-7, IL-10, TNF- $\alpha$, etcétera).

c) Los hallazgos radiológicos son parte del grupo B: confirmación de neumonía con características específicas. La confirmación radiológica deberá hacerse por medio de tomografía de tórax. En etapas tempranas aparece imagen en vidrio despulido (esmerilado), con alteración principalmente intersticial, con la progresión de la enfermedad aparecen consolidaciones diseminadas o en parche, y cuando es tan grave aparecen grandes consolidaciones lobares. Una característica distintiva es la ausencia de derrame pleural. Se han descrito hasta cinco etapas de evolución radiológica que se presentan hasta en $80 \%$ de los afectados:

I. Ultratemprana: sin síntomas, ni alteraciones de laboratorio, hallazgos radiológicos mínimos, como algo de broncograma, crecimientos ganglionares centrales, puede haber focos únicos de radioopacidad en vidrio esmerilado. 
II. En los primeros tres días de enfermedad con síntomas, hay exudado alveolar y se observan imagen de afectación intersticial y se nota claramente las imágenes en vidrio despulido.

III. Existe una progresión rápida de los cambios radiológicos, ocurre entre tres y siete días. Hay consolidaciones en parche, vidrio despulido y afectación intersticial diseminada.

IV. La progresión de la lesión es mayor, con depósito de fibrina alveolar, grandes zonas de consolidación del tejido pulmonar.
V. Hay engrosamiento de tabiques alveolares, septales e interlobulares, grandes zonas de consolidación y lesión alveolar.

De acuerdo a los hallazgos en individuos afectados por la enfermedad, las anormalidades en la tomografía pueden progresar rápidamente, teniendo su punto máximo entre los seis y 11 días de iniciado los síntomas, siendo el hallazgo más característico la imagen en vidrio despulido (esmerilado), misma que persiste en un porcentaje alto de los individuos recuperados (Figuras 3 A y $B$ ).
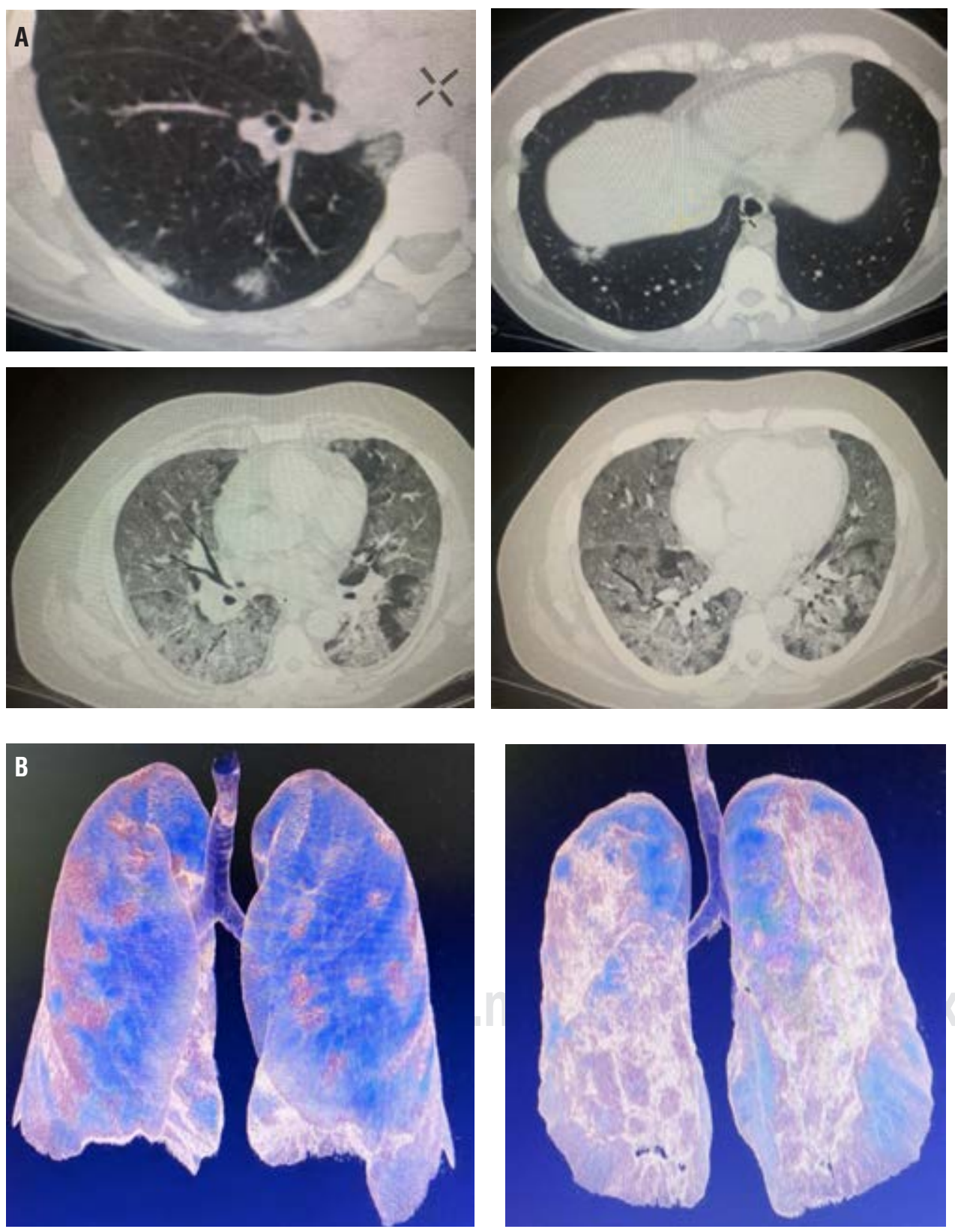

Figura 3:

Hallazgos tomográficos de neumonía por SARS-CoV-2. A) Imágenes de TAC de tórax, de la fototeca del Acad. Dr. Raúl Carrillo Esper, fueron editadas para proteger la identidad de los pacientes mexicanos con diagnóstico confirmado de COVID-19. B) Imágenes de reconstrucción 3D de TAC de tórax, de la fototeca del Dr. Pedro Ramírez Ambriz, fueron editadas para proteger la identidad de los pacientes mexicanos con diagnóstico confirmado de COVID-19. 

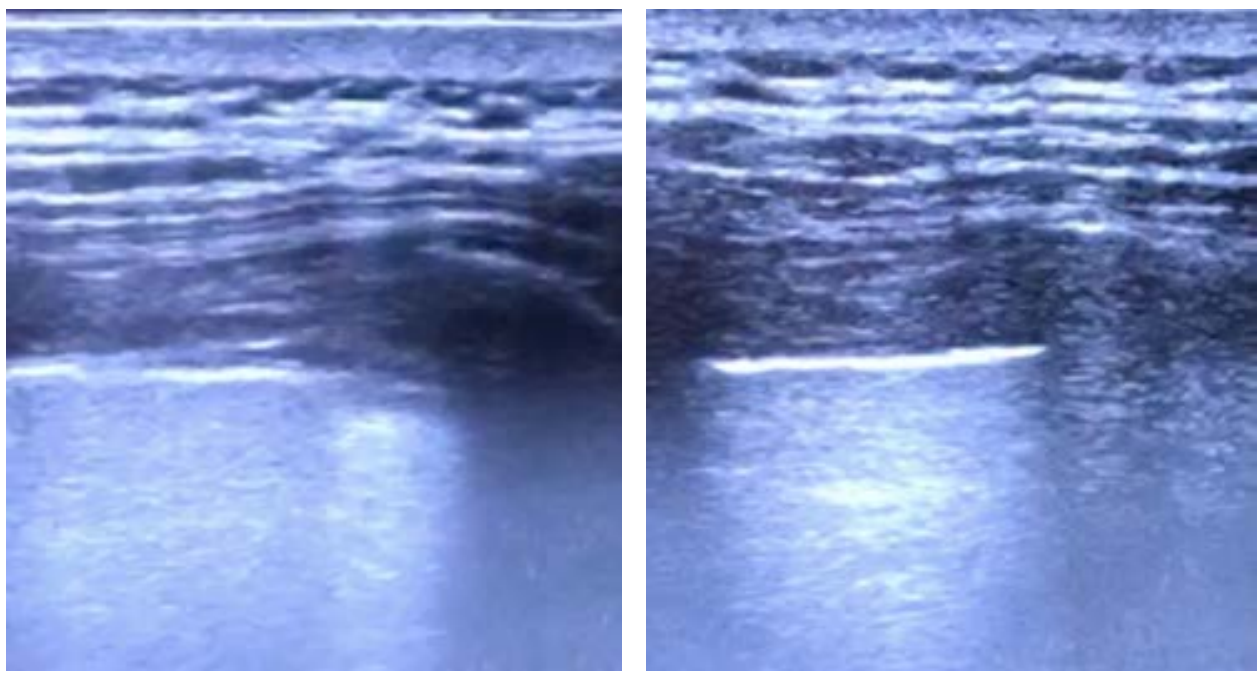

Figura 4:

Hallazgos sonográficos de la neumonía por SARS-CoV-2.

Imágenes de ultrasonido pulmonar. De la fototeca del Acad. Dr. Raúl Carrillo Esper, fueron editadas para proteger la identidad de los pacientes mexicanos con diagnóstico confirmado de COVID-19.

En tiempo real se observa el movimiento irregular de la línea pleural y la formación de patrón B. Vídeos disponibles con el autor.

Tabla 1: Muestras biológicas para la confirmación de COVID-19.

\begin{tabular}{|c|c|c|c|c|}
\hline Tipo de muestra & Material & $\begin{array}{l}\text { Temperatura } \\
\text { de transporte }\end{array}$ & Almacenamiento & Comentarios \\
\hline $\begin{array}{l}\text { Exudado faríngeo y } \\
\text { nasofaríngeo }\end{array}$ & $\begin{array}{l}\text { Medio de transporte viral } \\
\text { Hisopos de dacrón o rayón con } \\
\text { mango de plástico (exudado } \\
\text { faríngeo) } \\
\text { Hisopos de dacrón o rayón con } \\
\text { mango flexible (exudado nasofa- } \\
\text { ríngeo) }\end{array}$ & $2-8^{\circ} \mathrm{C}$ & $\begin{array}{l}\leq 5 \text { días: } 2-8{ }^{\circ} \mathrm{C} \\
>5 \text { días: }-70^{\circ} \mathrm{C}\end{array}$ & $\begin{array}{l}\text { El exudado faríngeo y nasofa- } \\
\text { ríngeo se deben colocar en el } \\
\text { mismo tubo para incrementar la } \\
\text { carga viral }\end{array}$ \\
\hline Lavado bronquioalveolar & $\begin{array}{l}\text { Contenedor estéril con medio de } \\
\text { transporte viral }\end{array}$ & $2-8^{\circ} \mathrm{C}$ & $\begin{array}{l}\leq 48 \text { horas: } 2-8^{\circ} \mathrm{C} \\
>48 \text { horas: }-70^{\circ} \mathrm{C}\end{array}$ & $\begin{array}{l}\text { Puede haber dilución del pató- } \\
\text { geno, pero aun así vale la pena } \\
\text { tomarla. Se requiere como mínimo } \\
2 \mathrm{~mL} \text { ( } 1 \mathrm{~mL} \text { de lavado bronquioal- } \\
\text { veolar más } 1 \mathrm{~mL} \text { de medio de } \\
\text { transporte) }\end{array}$ \\
\hline $\begin{array}{l}\text { Aspirado traqueal, } \\
\text { aspirado nasofaríngeo o } \\
\text { lavado nasal }\end{array}$ & $\begin{array}{l}\text { Contenedor estéril con medio de } \\
\text { transporte viral }\end{array}$ & $2-8^{\circ} \mathrm{C}$ & $\begin{array}{l}\leq 48 \text { horas: } 2-8^{\circ} \mathrm{C} \\
>48 \text { horas: }-70^{\circ} \mathrm{C}\end{array}$ & $\begin{array}{l}\text { Se requiere como mínimo } 2 \mathrm{~mL} \\
\text { (1 mL de aspirado, más } 1 \mathrm{~mL} \text { de } \\
\text { medio de transporte) }\end{array}$ \\
\hline Biopsia de pulmón & $\begin{array}{l}\text { Contenedor estéril con medio de } \\
\text { transporte viral }\end{array}$ & $2-8^{\circ} \mathrm{C}$ & $\begin{array}{l}\leq 5 \text { dias: } 2-8^{\circ} \mathrm{C} \\
>5 \text { días: }-70^{\circ} \mathrm{C}\end{array}$ & $\begin{array}{l}2 \mathrm{~cm}^{3} \text { de la parte visiblemente } \\
\text { más afectada }\end{array}$ \\
\hline
\end{tabular}

Tomada sin modificaciones del Lineamiento Estandarizado para la Vigilancia Epidemiológica y por Laboratorio de COVID-19. Secretaría de Salud. México, 2019.

La ultrasonografía puede ser considerada como una herramienta útil a la cama del paciente, tiene la facilidad del acceso rápido sin necesidad de la movilización y el riesgo de contaminación en otras áreas hospitalarias, más en aquellos individuos con altos requerimientos de soporte ventilatorio o inestabilidad hemodinámica. Los hallazgos más característicos son:

I. Engrosamiento de la línea pleural, que es irregular, con derrames pleurales poco frecuentes.

II. Patrones de líneas B, en diferentes variedades, focales, multifocales y confluentes.
III. Consolidaciones en patrones multifocales pequeñas, no translobares, translobares, con broncograma aéreo móvil y afectación multilobar.

IV. Patrón A durante la fase de recuperación (Figura 4).

3. Grupos de riesgo: niños menores de cinco años, adultos mayores de 60 años, enfermedades pulmonares previas, enfermedad cardiovascular, nefropatía, hepatopatía, enfermedades hematológicas, diabetes mellitus incluyendo gestacional, inmunosupresión por medicamentos, personas con infección por VIH (virus de la inmunodeficiencia 
humana), mujeres embarazadas y hasta dos semanas del postparto, obesidad y en general todos los que tienen algún grado de alteración del sistema inmunológico.

4. La confirmación diagnóstica debe hacerse lo más temprano posible, en las etapas iniciales de la enfermedad se recomienda que la muestra sea del tracto respiratorio, debido a que el número de copias virales es más alto y es posible que la prueba en sangre resulte falso negativo. Las muestras útiles son las obtenidas por aspirado transtraqueal, lavado broncoalveolar, aspirado nasofaríngeo y raspado con hisopo. Existen alrededor de siete pruebas moleculares para el rastreo específico del material genético del virus, todas basadas en la reacción de polimerasa en cadena (RPC) (Tabla 1).

La muestra deberá tomarse de manera obligatoria por personal capacitado y designado exclusivamente para este procedimiento. Las muestras deberán ser consideradas como altamente infecciosas, por lo que es indispensable portar el equipo de protección personal mínimo necesario, (respiradores NIOSH N95 o N100, lentes con protección lateral, bata desechable de manga larga e impermeable, doble par de guantes de nitrilo, cinta microporosa, zapato de seguridad o cubre zapato, gorros, etcétera).
Recientemente, en febrero de 2020, se presentaron las características clínicas de los individuos afectados en China de más de 500 hospitales, se mostró que la mayoría de los infectados tienen una enfermedad de leve a moderada, con síntomas inespecíficos. Sólo alrededor de $6 \%$ requirió hospitalización en una Unidad de Cuidados Intensivos (UCI), el promedio de edad de estos individuos era de 63 años, con tasa de prevalencia mayor de enfermedades crónicas como hipertensión $35 \%$, diabetes $26.9 \%$ y EPOC $10 \%$, teniendo este grupo menores tiempos de incubación de la enfermedad, de hasta cuatro días. El SIRA afectó hasta $40 \%$ de los pacientes en la UCI, $60 \%$ de los individuos requirió ventilación mecánica, la disfunción renal aguda apareció en $6 \%$ y el choque séptico en $13.4 \%$, con una tasa de mortalidad arriba de $22 \%$, comparada con los no tratados en la UCI que fue de $1.4 \%$, la disfunción hepática también ha sido reportada hasta en $29 \%$ de los tratados en UCI.

\section{RECOMENDACIONES GENERALES DE TRATAMIENTO}

1. La mayoría de los afectados tendrá una enfermedad leve, por lo que deberá cumplirse aislamiento domiciliario, y

Tabla 2: Medidas de precaución para el personal de salud.

Precauciones estándar (tarjeta color rojo)

- Higiene de manos. Lavado de manos con agua y jabón o higiene de manos con alcohol gel en concentraciones mayores al $70 \%$ en los cinco momentos establecidos de acuerdo a la OMS

- Uso de guantes cuando haya contacto con líquidos corporales (sangre y secreciones), artículos contaminados, membranas mucosas y heridas en la piel

- No olvidar el lavado de manos antes de colocar los guantes y después de quitarlos

- Usar mascarilla con protección facial cuando haya riesgo de salpicaduras de sangre $u$ otros líquidos corporales en ojos y cara (aerosoles)

- Uso de bata impermeable si hay riesgo de salpicaduras para prevenir la contaminación de la piel y ropa

- Transportar la ropa contaminada dentro de bolsa de plástico de color rojo

- Uso de contenedores rígidos (RPBI) para el desecho de agujas y material punzocortante

- Nunca volver a encapuchar las agujas
Medidas de aislamiento por gotas (tarjeta color verde)

- Mantener una distancia de un metro con el paciente

- Mantener la puerta cerrada durante la atención

- Visitantes reportarse a central de enfermeras antes de tener contacto con el paciente

- Equipo médico desechable o personalizado, por ejemplo: estetoscopio, manguitos de presión arterial y termómetros, si el equipo necesita ser compartido entre pacientes, limpiar y desinfectar entre cada uso con alcohol etílico al $70 \%$

- Habitación individual cuando se tenga disponible o llevar a cabo aislamiento de cohorte

Medidas de precaución por aerosoles (tarjeta color azul)

- El uso de respiradores N95 únicamente cuando al paciente se le realicen procedimientos que generen aerosoles, (aspiraciones, intubaciones, broncoscopías y reanimación cardiopulmonar). De igual forma utilizar estas medidas ante la presencia de un caso confirmado

- Transportar al paciente sólo para propósitos indispensables y el paciente deberá portar mascarilla quirúrgica desechable

- Notificar al área que reciba al paciente sobre las precauciones

Tomada sin modificaciones del Lineamiento Estandarizado para la Vigilancia Epidemiológica y por Laboratorio de COVID-19. Secretaría de Salud. México, 2019. 
Vestido

1
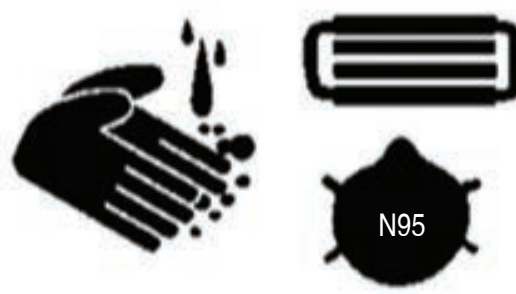

3
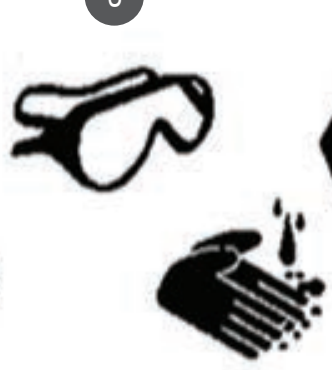

(1)
4

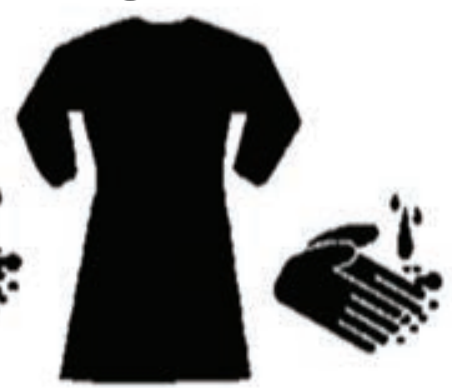

(1)
5

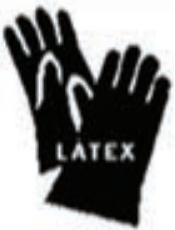

Orden de colocación

\begin{tabular}{|c|c|c|c|c|c|c|c|}
\hline $\begin{array}{l}\text { Higiene } \\
\text { de manos }\end{array}$ & $\begin{array}{l}\text { Protección } \\
\text { respiratoria }\end{array}$ & $\begin{array}{c}\text { Higiene } \\
\text { de manos }\end{array}$ & $\begin{array}{c}\text { Protección } \\
\text { ocular }\end{array}$ & $\begin{array}{c}\text { Higiene } \\
\text { de manos }\end{array}$ & Bata & $\begin{array}{l}\text { Higiene de } \\
\text { manos }\end{array}$ & Guantes \\
\hline
\end{tabular}

Desvestido

(6)

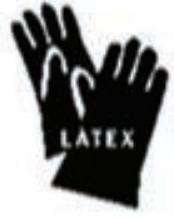

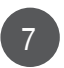

8

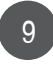

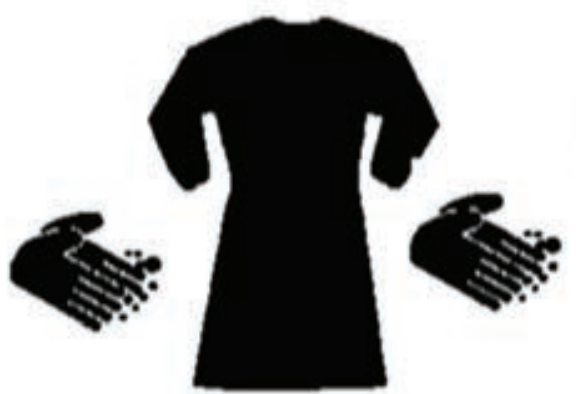

10

11
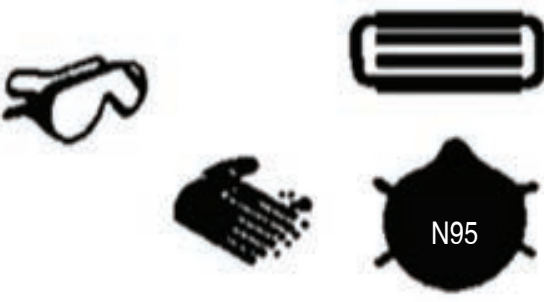

12

13

\section{Orden de retiro}

Desinfectar con toalla alcoholada, retiro de guantes
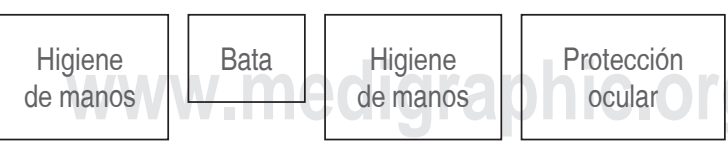

\section{Protección \\ respiratoria}

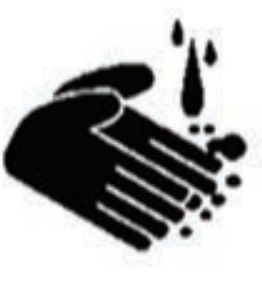

Figura 5: Secuencia de colocación y retiro de equipo de protección personal.

Tomada sin modificaciones del Lineamiento Estandarizado para la Vigilancia Epidemiológica y por Laboratorio de COVID-19. Secretaría de Salud. México, 2019. 
sólo requiere tratamiento sintomático. Se indican medidas de monitoreo por la aparición de síntomas de gravedad como la disnea, particularmente a los individuos con factores de riesgo.

2. Los pacientes que desarrollan neumonía requieren de atención en un centro especializado, la mayoría requieren oxígeno suplementario y se recomienda mantener el porcentaje de $\mathrm{SpO}_{2}$ (oximetría de pulso) en más del $90 \%$ para adultos y niños sin enfermedades cardiovasculares, cerebrales o pulmonares previas, en embarazadas más del $95 \%$, y niños y adultos con enfermedades previas mantener alrededor del 94\%.

3. Los individuos que progresan rápidamente con hipoxemia, hipercapnia, cianosis, choque, etcétera, pueden ser candidatos al uso de ventilación mecánica no invasiva (VMNI) o terapia de oxígeno con alto flujo. La OMS recomienda que si después de una hora del uso de cualquiera de éstas no hay mejoría, deberá utilizarse ventilación mecánica invasiva; además, se debe considerar que el uso de las terapias no invasivas son un factor de riesgo para la generación de aerosoles y aumentan el riesgo de transmisión al personal de la salud.

4. Los pacientes bajo ventilación mecánica invasiva deben someterse a un protocolo en el que la secuencia de ventilación otorgue medidas satisfactorias de protección alveolar, uso adecuado de PEEP (presión positiva al final de la espiración), evitar asincronías con la secuencia ventilatoria, $\mathrm{FiO}_{2}$ mínimo necesario, monitoreo de la presión meseta, presión media, presiones pico, resistencias, compliancia, etcétera, en resumen evitar la lesión pulmonar por el mal uso, programación y falta de monitoreo de la secuencia ventilatoria.

5. Considerar el uso de la ventilación en decúbito prono, por intervalos de 12 horas al día, sin aumentar el riesgo de desconexión del circuito de ventilación, así como inestabilidad hemodinámica.

6. En la actualidad no hay evidencia clara del uso de ECMO en los individuos afectados, además de que se necesitan centros especializados con experiencia y recursos técnicos, materiales y humanos adicionales, que de acuerdo a algunos expertos no son aplicables en casos de saldos masivos de enfermos.

7. En la actualidad y hasta el término de la redacción de este documento, no existen recomendaciones basadas en evidencia clara y contundente de un tratamiento farmacológico específico contra el virus.

8. El tratamiento del estado de choque séptico deberá guiarse de acuerdo a los lineamientos establecidos, basados en la evidencia científica disponible.

9. Es de prioridad y antes de realizar cualquier procedimiento, y aún más cuando el procedimiento pueda involucrar el contacto con aerosoles, el apego estricto al lavado de manos, uso de alcohol gel y el uso adecuado del equipo de protección personal. Consultar lineamientos nacionales e internacionales (Tabla 2 y Figura 5).

a) Uso de mascarillas ajustadas tipo N95 o FFP2, bata impermeable, guantes, protección ocular, careta o gafas de seguridad.

b) Realizar los procedimientos que generen aerosoles en un cuarto de presión negativa.

10. Consultar los lineamientos internacionales y regionales sobre el desecho adecuado de los fluidos corporales de los individuos infectados, así como del manejo de los cadáveres.

\section{CONCLUSIONES}

Sin duda la aparición de esta pandemia es un gran reto en todos los ámbitos: político, social, económico, médico, etcétera; viene a dar un fuerte golpe a la realidad, nos ha demostrado cómo los sistemas médicos mejor calificados, más avanzados, con mayores recursos tecnológicos y humanos, se ven rebasados por la gran morbimortalidad de esta enfermedad. No hay duda que tendremos que regresar al pasado, como en 1847 cuando Ignaz Semmelweis se dio cuenta que el lavado con jabón y el uso de una solución antiséptica (hipoclorito cálcico) eliminaba el olor a «cadáver» de las manos de estudiantes y médicos, y así evitaba la transmisión de «miasmas» a las mujeres parturientas. Alrededor de $60 \%$ de los profesionales de salud olvidamos, omitimos o no creemos en el lavado de manos, ahora peleamos por tener grandes reservas de jabón, suficiente agua y hasta fabricamos alcohol gel sin tener medidas necesarias de precaución. La sociedad ha vuelto a ver, considero de manera hipócrita, al personal de la salud como héroes, cuando meses antes éramos blanco de agresiones, demandas, etcétera. Tal vez ahora sea la oportunidad de darnos cuenta que como sociedad nuestros malos hábitos son la causa de que el país tenga una pandemia más grave, y con ello me refiero a diabetes, hipertensión, obesidad, EPOC, enfermedades cardiovasculares, deterioro cognitivo, etcétera; enfermedades que a diario causan miles de muertes por complicaciones graves, incluyendo COVID-19.

La naturaleza es sabia y cuando actúa es contundente (SARS-CoV-2 debe ser un medio), ya que lo ha demostrado en las últimas semanas: menos contaminación ambiental, aguas limpias, menos basura. Quizá esta pandemia sea el sueño cumplido de nuestro querido planeta que solicita un respiro a la peor plaga que ha existido: el ser humano soberbio y con ambición de poder, que no ha entendido que más allá de soñar con colonizar la Luna y Marte debe reconocer su fragilidad. 


\section{REFERENCIAS}

1. World Health Organization Press Conference. The World Health Organization (WHO) Has Officially Named the Disease Caused by the Novel Coronavirus as COVID-19. Available online: https://www.who. int/emergencies/diseases/novel-coronavirus-2019.

2. Jin $\mathrm{Y}$, Yang $\mathrm{H}$, Ji W, Wu W, Chen $\mathrm{S}$, Zhang W, et al. Virology, epidemiology, pathogenesis, and control of COVID-19. Viruses 2020;12. doi: 10.3390/v12040372.

3. Wu A, Peng Y, Huang B, Ding X, Wang X, Niu P, et al. Genome composition and divergence of the novel coronavirus (2019-nCoV) originating in China. Cell Host Microbe. 2020;27:325-328.

4. Lu R, Zhao X, Li J, Niu P, Yang B, Wu H, et al. Genomic characterization and epidemiology of 2019 novel coronavirus: Implications for virus origins and receptor binding. Lancet. 2020;395:565-574

5. Novel Coronavirus Pneumonia Emergency Response Epidemiology Team. Vital surveillances: the epidemiological characteristics of an outbreak of 2019 novel coronavirus diseases (COVID-19)-China, 2020. China CDC Weekly. (Accessed February 20, 2020). Available in: http://weekly. chinacdc.cn/en/article/id/e53946e2-c6c4-41e9-9a9bfea8db1a8f51.

6. Chen L, Liu W, Zhang Q, Xu K, Ye G, Wu W, et al. RNA based mNGS approach identifies a novel human coronavirus from two individual pneumonia cases in 2019 Wuhan outbreak. Emerg Microbes Infect. 2020;9:313-319. doi: 10.1080/22221751.2020.1725399.

7. Cui J, Li F, Shi ZL. Origin and evolution of pathogenic coronaviruses. Nat Rev Microbiol. 2019;17:181-192. doi: 10.1038/s41579-018-0118-9.

8. Wu Z, McGoogan JM. Characteristics of and important lessons from the coronavirus disease 2019 (COVID-19) outbreak in China: summary of a report of 72314 cases from the Chinese Center for Disease Control and Prevention. JAMA. 2020;323:1239-1242.

9. Liu Y, Yang Y, Zhang C, Huang F, Wang F, Yuan J, et al. Clinical and biochemical indexes from 2019-nCoV infected patients linked to viral loads and lung injury. Sci China Life Sci. 2020;63:364-374.

10. Batlle D, Wysocki J, Satchell K. Soluble angiotensin-converting enzyme 2: a potential approach for coronavirus infection therapy? Clin Sci (Lond). 2020;134:543-545.
11. Bavishi C, Maddox TM, Messerli FH. Coronavirus disease 2019 (COVID-19) infection and renin angiotensin system blockers. JAMA Cardiol. 2020. doi: 10.1001/jamacardio.2020.1282. [Epub ahead of print].

12. Li W, Moore MJ, Vasilieva N, Sui J, Wong SK, Berne MA, et al. Angiotensin-converting enzyme 2 is a functional receptor for the SARS coronavirus. Nature. 2003;426:450-454.

13. Lineamiento estandarizado para la vigilancia epidemiológica y por laboratorio de COVID-19. Disponible en: https://www.gob.mx/salud/ documentos/nuevo-coronavirus.

14. Wujtewicz MA, Dylczyk-Sommer A, Aszkiełowicz A, Zdanowski S, Piwowarczyk S, Owczuk. COVID-19-what should anaethesiologists and intensivists know about it? Anaesthesiol Intensive Ther. 2020;52:1-18.

15. Alhazzani W, Møller MH, Arabi YM, Loeb M, Gong MN, Fan E, et al. Surviving sepsis campaign: guidelines on the management of critically ill adults with coronavirus disease 2019 (COVID-19). Intensive Care Med. 2020;28:1-34. doi: 10.1007/s00134-020-06022-5. Epub ahead of print. PMID: 32222812; PMCID: PMC7101866.

16. Arabi YM, Murthy S, Webb S. Correction to: COVID-19: a novel coronavirus and a novel challenge for critical care [published online ahead of print, 2020 Mar 18]. Intensive Care Med. 2020;46:1-2. doi: 10.1007/s00134-020-06009-2.

17. Bouadma L, Lescure FK, Lucet JC, Yazdanpanah Y, Timsit JF. Severe SARS-CoV-2 infections: practical considerations and management strategy for intensivists Intensive Care Med. 2020;46:579-582.

18. McCloskey B, Heymann DL. SARS to novel coronavirus: old lessons and new lessons. Epidemiol Infect. 2020; 148: e22. doi: 10.1017/ S0950268820000254.

19. Peng QY, Wang XT, Zhang LN. Chinese Critical Care Ultrasound Study Group (CCUSG). Findings of lung ultrasonography of novel corona virus pneumonia during the 2019-2020 epidemic. Intensive Care Med https://doi.org/10.1007/s00134-020-05996-6.

20. Zhang W. Imaging changes in severe COVID-19 pneumonia. Intensive Care Med. 2020;46:583-585. https://doi.org/10.1007/s00134-02005976-w. 